\title{
Keynote for Fast Publishing by Writing Technical Note
}

\section{Type of Article: Editorial}

\begin{abstract}
Abdeldjalil KHELASSI
Editor-in-chief Medical Technologies Journal

Abstract:

Writing-up of technical information is consuming time and efforts, however the exponential grow of innovations and finding should be relevantly shared by publications. Technical note (also known as innovation or technical development in some journals) is among short scientific article published by medical journals and sometime engineering journals. It is produced for describing a new technic, procedure, or development relevant for medical system. Sometimes, technical note describes the modification of an existing technics. This article presents a simple guide on writing Technical Notes and includes basic arguments as definition, appellations, and structure.

Keywords: Publishing, Technical Note, Scientific writing.
\end{abstract}

Corresponding author: Abdeldjalil KHELASSI, Abou Beker Belkaid University of Tlemcen, Algeria., khelassi.a@gmail.com

@2017-2019 KNOWLEDGE KINGDOM PUBLISHING.

\section{1- Introduction}

\subsection{Background}

The scientific innovation is in progress very fast. The patents application grows to more than three million applications by 2017 worldwide [1]. The number of worldwide patents in medical technology is 118710 only in 2016 that represent $4.5 \%$, adding to biotechnology 55479 and pharmaceuticals 106704, to attend $10.6 \%$ [1]. Although not all patents represent innovation and not all innovations are represented by patents, the technical note still the most used publication channel for innovations [1]. It is due to its easy form of publication and the big impact of journals against intellectual property organizations.

Publication, which could be open access or embargo, is also very fast. Only Medline database contains more than 26 million records [2] from 5,639 selected publications [3] covering biomedicine and health from 1950 to the present. In addition, more than 1.3 million publication recorded only in 2018 [2-3], and very useful, more than 27 million citations recorded in 2018 [3].

The publication should respect some standards criteria to be accepted and reused in the scientific community. From the coherent content, correct structure standards, to the reputed channels. The technical note stills helping the technologic evolution. It is a short scientific publication called technical note, innovation, or technical development describing a technical process [4]. This paper presents some notes about writing technical notes. We focus this area by including the basic arguments as definition, appellations, and structure.

\subsection{Definition}

Technical Note is a research article, very short with few references and figures. It is mainly written to describe a new process, technic, or device in clinical medicine or management. It is also used to describe an upgrade of an existing process, technic, or device. The description should be validated by a software tool presentation or experimental computational method [4-6]. 


\subsection{Appellation}

Several journals publish technical notes, but some of them publish these research articles in another appellation. For example, the technical note is called innovations in some ophthalmology journals. It is also called technical developments in some imaging journals [4]. Some of them keep the appellation of original article for technical note some time the authors specify that it is a technical note on the title and some time without specification.

\section{Structure of technical note}

Technical notes follow the same structure as other original articles (Table1), they begin with a short abstract followed by introduction, material and methods, results, discussion and conclusion. Sometime the sections method and results are regrouped in only one section called technic. The specificity of these articles is only the maximum of words number is very small, few figures and few references are permitted [4].

Table 1: Technical note structures: two approach proposed by journal editors.

\begin{tabular}{|l|l|}
\hline Approach 1 & Approach 2 \\
\hline Title & Title \\
Abstract & Abstract \\
Keywords & Keywords \\
Introduction & Introduction \\
Material and Methods & Technic \\
Results & Discussion \\
Discussion & Conclusion \\
Conclusion & References \\
References & \\
\hline
\end{tabular}

\subsection{Title, abstract, and keywords}

The title is the most important piece of an article. It is very important to introduce all-important concepts on the title to attract readers to read the contents. It almost contains a subtitle, which describe the type of the contribution or an additional information explaining the meaning of the title. The abstract is the head text of each scientific article. It represents a short description of the contents. It describes also the most important information in the article as the aim, methods, results and conclusions [7-9]. Several forms are used in the literature for writing an abstract in which thirteen ways are indexed in [7]. The choice depends essentially about the article type and the journals standard. Now days, for technical note the journals requested the structured and graphical abstract and some journals request both of them. Finally, there should be 3-5 keywords at the end of the abstract, which describe the domains and research concerned by the article. These words are very useful in the article indexing and retrieving. There is a vocabulary thesaurus of medical key words controlled by National Library of Medicine NLM: Medical Subject Headings MeSH. 


\subsection{Body of technical note}

\subsubsection{Introduction}

A brief section provides the background and context of the innovation or development. The aim, features, and usefulness should be introduced in this section. If it is a subject of upgrading an existing innovation, then relevant critics of the old innovation and the advantages of the increment or modification should be highlighted.

\subsubsection{Methods}

This section describes all technic development and validation methods. All the life cycle of the innovation should be described (The analyze, the design, the realization and the tests). All technical details (data, components, manufacturers) must be provided to facilitate the reproduction of the technic. It should describe the manner that the technic or innovation was tested and validated, by introducing experiments materials, self-developed components, references of used components and their licenses. Other technical details should be introduced according to the described technic or innovation like equipment, suppliers ..etc. Illustrations via schematics, photographs, line drawing, block diagrams are well recommended in this section.

\subsubsection{Results}

This section should describe the findings of the test and validation experiments. However, some technical notes regrouped this section with the previous section in only one section entitled technic. The achieved results should be presented clearly to prove the strongest sides of the innovation. This presentation could be done by text, figures, and tables. According to the survey, sometime the statistical analysis is very necessary.

\subsubsection{Discussion}

This section is to explain the function and performance of the innovation. It is limited and short than in an original article. It must be confined to the specific message of the innovation. This section must highlight the value and contribution of the clinical diagnosis or management.

\subsubsection{Conclusion}

This section summarizes the usefulness of the technic or innovation. Limitation and perspectives could be added in this section. Some journals do not suggest this section because the previous section, discussion, is sufficient.

\subsubsection{Writing acknowledgments}

It is an optional section. All contributors that not have the quality of authors should be acknowledged in this section. The acknowledgments could be anonymous for peoples who participate in the experiments like patients, and equipment owners.

\subsubsection{Organizing references}

This section includes the used references. The form of references should follow the suggestions of the journal editor. The list of references should be short and restraint only to the used and recent ones.

\section{Ethics of technical notes}

The publishing ethics is a common argument for all type of contributions. As a scientific article, the technical note must follow the ethics suggested by the institutional ethics committee and journal editor. It is very difficult to restraint the publishing ethics in a defined list, but in the literature, we find these arguments accepted and published by the Committee Of Publication Ethics COPE: - Duplicate 
publication, Data reproduction, Salami publishing, Plagiarism, Authorship problems, etc

The ethics arguments are very difficult to be detected by editors then it is the responsibility of authors to respect these ethics.

\section{Conclusion}

The technical note, innovation, or technical development is a short scientific article describing an innovation, technic or development process. It is very important for industry and health science to schedule technical notes in their notes due to the simplicity of editing and their important impact. This article describes the important arguments of publishing a technical note in higher standards.

\section{Conflict of interest statement}

We certify that there is no conflict of interest with any financial organization in the subject matter or materials discussed in this manuscript.

\section{Acknowledgements:}

The author sincerely thanks Dr. Mehrdad Jalalian for reviewing the paper and providing insightful comments.

\section{Author biographies}

Dr Abdeldjalil Khelassi: is an Associate Professor at Tlemcen University, Algeria. He obtained his Doctor in Science (2013), Magister (2008) and Engineer (2004) in Computer Sciences from the Department of Computer Science at Tlemcen University. His research interest includes cognitive systems, knowledge-based systems, case-based reasoning, distributed reasoning, fuzzy sets theory and health science. He is the editor manager of Medical Technologies Journal and the co-editor in chief of Electronic Physician Journal.

\section{Reference}

[1] World Intellectual Property Indicators 2018, WIPO Report, URL: http://www.wipo.int Retrieved 2019-06-30.

[2] "Pubmed all[sb]". NLM Systems.URL: https://www.ncbi.nlm.nih.gov/pubmed/Retrieved 2019-06-30.

[3] "- Statistical Reports on MEDLINE®/PubMed $®$ Baseline Data". NLM. URL: https://www.nlm.nih.gov/bsd/num_titles.html 2019-06-30. Retrieved 2019-06-30.

[4] Ng, K. H., \& Peh, W. C. (2010). Writing a technical note. Singapore medical journal, 5l(2), 101-3. PMID: 20358146

[5] KHELASSI, A., Tchenar, M., \& Rahali, Y. (2017). Contextual hybrid-based recommendation of Pubmed articles. Medical Technologies Journal, 1(2), 15-24. doi: 10.26415/2572-004X-vol1iss2p15-24

[6] Olson, Dewey E (1967). "From Engineering Notebook to Technical Note." Technical Communication, vol. 14, no. 1, 22-23. URL: www.jstor.org/stable/43151328. Retrieved 2019-06-30.

[7] Hartley, J., \& Cabanac, G. (2017). Thirteen Ways to Write an Abstract. Publications, 5(2), 11. DOI : https://doi.org/10.3390/publications5020011 
Medical Technologies Journal, Volume: 3, Issue: 2, April-June 2019, Pages: 413-417. Doi :

https://doi.org/10.26415/2572-004X-vol3iss2p413-417

[8] Jalalian Hosseini, M. (2017). How to Write Scientific Journals of the Highest Standards. Medical Technologies Journal, 1(1), 6-6. doi: 10.26415/2572-004X-vol1iss1p6-6

[9] Jalalian, M. (2012). Writing an eye-catching and evocative abstract for a research article: A comprehensive and practical approach. Electronic Physician, 4(3), 520-524. 